\title{
Lipid-based nanostructures as a strategy to enhance curcumin bioaccessibility: Behavior under digestion and cytotoxicity assessment
}

\author{
Raquel F.S. Gonçalves ${ }^{a}$, Joana T. Martins ${ }^{\mathrm{a}}$, Luís Abrunhosa ${ }^{\mathrm{a}}$, João Baixinho ${ }^{\mathrm{b}}$, Ana A. Matias ${ }^{\mathrm{b}}$, \\ António A. Vicente ${ }^{a}$, Ana C. Pinheiro ${ }^{\text {a," }}$ \\ ${ }^{\text {a }}$ CEB - Centre of Biological Engineering, University of Minho Campus de Gualtar, 4710-057 Braga, Portugal \\ ${ }^{\mathrm{b}}$ IBET - Institute of Experimental Biology and Technology, Avenida da República, Quinta-do-Marquês, Estação Agronómica Nacional, Apartado 12, 2781-901 Oeiras, \\ Portugal
}

\section{A R T I C L E I N F O}

\section{Keywords:}

Nanoemulsions

Nanostructured lipid carriers

Solid lipid nanoparticles

In vitro static digestion

Intestinal permeability

Lipid physical state

\begin{abstract}
A B S T R A C T
The aim of this study was to evaluate the behavior of different lipid-based nanostructures during in vitro digestion, in particular on curcumin's bioaccessibility, and to access their potential toxicity. Solid lipid nanoparticles (SLN), nanostructured lipid carriers (NLC) and nanoemulsions (NE) were submitted to harmonized static in vitro digestion and their cytotoxicity and cellular transport were evaluated using Caco-2 cell line.

NE presented the highest curcumin's bioaccessibility followed by NLC and SLN, 71.1\%, 63.7\% and 53.3\%, respectively. Free fatty acids percentage increased in the following order: NLC $\leq$ NE $<$ SLN. Non-digested nanostructures and excipients presented no cytotoxicity; however, digested NE and NLC presented cytotoxicity due to MCT oil, which presented cytotoxicity after digestion. The apparent permeability coefficient of NLC was higher than SLN and NE.

These results showed that lipid-based nanostructures' physical state and composition have a high influence on particles' behavior during digestion, and on their cytotoxicity/intestinal permeability, and highlights the importance of conducting cytotoxicity assessments after in vitro digestion.

This work contributes to a better understanding of the behavior of lipid-based nanostructures under digestion/ adsorption, and this knowledge will be useful in design of nanostructures that afford both safety and an increased bioactive compounds' bioavailability.
\end{abstract}

\section{Introduction}

Curcumin is a lipophilic polyphenolic compound derived from turmeric (Curcuma longa), widely known by its broad range of healthpromoting functions, including anti-inflammatory, anticarcinogenic, antimicrobial and antioxidant activities (Chang et al., 2019; Perrone et al., 2015). Therefore, it is catching considerable attention from food scientists due to its potential use as a natural antioxidant and antimicrobial on beverages and functional foods (Tang, 2020). However, despite the established curcumin beneficial effects, its applications in food products are hindered by its poor solubility and quick degradation on aqueous solution (Gómez-Estaca, Balaguer, López-Carballo, Gavara, \& Hernández-Muñoz, 2017). In addition, its poor absorption, high chemical instability, metabolic degradation during physiological transit, metabolic end-products inactivity, accumulation within epithelial intestine cells and its rapid elimination from the body results in a very low bioavailability (Faralli, Shekarforoush, Ajalloueian, Mendes, \& Chronakis, 2019).

In order to overcome these major drawbacks, different strategies have been undertaken to enhance curcumin solubility, stability and cellular permeability and consequently, improve its bioavailability. One of the most commonly used strategies is the encapsulation of curcumin on different nanostructured delivery systems. Particularly, it has been shown that different lipid-based nanostructures can be appropriate templates to encapsulate curcumin and improve its stability and bioavailability upon digestion (Nayak, Mills, \& Norton, 2016). Nanoemulsions (NE), defined as thermodynamically unstable small particles (radius $<100 \mathrm{~nm}$ ) comprising two immiscible liquids (with one of the liquids being dispersed in the other one), are particularly useful for this purpose. In fact, NE show significant advantages compared to macroemulsions, including increased transparency, high surface area (leading to a higher absorption), physical stability (to gravitational separation,

\footnotetext{
* Corresponding author.

E-mail address: anapinheiro@deb.uminho.pt (A.C. Pinheiro).
} 
flocculation and coalescence) and bioavailability (McClements, 2012). However, some NE limitations have been described namely, instability (e.g. Oswald ripening, creaming, flocculation, and coalescence) and the use of large amounts of surfactants to stabilize them (McClements, 2012). To overcome these limitations, more advanced lipid carriers, such as solid lipid nanoparticles (SLN) and nanostructured lipid carries (NLC) have been developed. SLN and NLC are formed by solid lipids formulated to improve bioactive compounds' stability, bioavailability and to modulate their release rate (Pimentel-Moral et al., 2018). SLN are characterized by the presence of a mixture of one or more solid lipids, being the bioactive compounds entrapped within the solid matrix, whereas, NLC are composed by a solid and liquid lipid mixture (Souto \& Doktorovová, 2009).

Although nanostructured delivery systems use has been reported as a promising technique to improve curcumin bioavailability as well as its physical and chemical stability, the use of sub-micro particles is raising safety concerns among consumers, regulatory agencies and food industry. In fact, depending on their composition, structure and properties, ingested nanostructured delivery systems may cause toxicity due to different mechanisms, such as i) interference with normal gastrointestinal functions, ii) accumulation within specific tissues; iii) cytotoxicity and cellular malfunction; iv) modification of bioactive compounds' release location; and v) interference with gut microbiota (McClements \& Xiao, 2017). Therefore, the evaluation of nanostructured delivery systems behavior once ingested will allow to optimize delivery systems' design (i.e. maximize curcumin intestinal absorption and therefore, its health benefits) and to assess their safety.

During the digestion process, the physical state of lipid-based nanostructures, among other characteristics, may influence some enzymatic and physicochemical processes, such as, droplet coalescence and disruption, interfacial composition, lipid digestibility and micelle solubilization, and consequently, the curcumin's bioavailability. In this context, three lipid-based nanostructures - NE, SLN and NLC - formulated with carrier oil at different physical states (i.e. liquid, solid and liquid/solid mixture, respectively) have been tested as strategies to enhance curcumin's bioavailability. These lipid-based nanostructures have been submitted to an in vitro harmonized static digestion, where their behavior has been evaluated in terms of lipid digestibility, curcumin's bioaccessibility, stability and effective bioavailability. Furthermore, the cytotoxicity of lipid-based nanostructures and their excipients were assessed before and after digestion protocol using Caco- 2 cell line as well as the cellular permeability. Such a complete study on the behavior of different lipid-based nanostructures under digestion and absorption has not been performed before.

\section{Materials and methods}

\subsection{Materials}

Beeswax produced by Apis mellifera was purchased from QUIMIND (Porto, Portugal), PHOSPHOLIPON ${ }^{\circledR}$ 90G, composed by $90 \%$ of phosphatidylcholine from soybean, and PHOSPHOLIPON ${ }^{\circledR} 80 \mathrm{H}$, composed by hydrogenated phospholipids from soybean with $70 \%$ phosphatidylcholine, were kindly provided by Lipoid (Switzerland). Neobee 1053 Medium Chain Triglycerides (MCTs) composed by caprylic/capric triglyceride oil with a fatty acid distribution of 55\% C8:0 and 44\% C10:0, was kindly provided by Stepan (The Netherlands). Curcumin, pepsin from porcine gastric mucosa $\left(\geq 2500 \mathrm{U} . \mathrm{mg}^{-1}\right)$, bile extract porcine, pancreatin from porcine pancreas (8x USP), Pefabloc ${ }^{\circledR}$ SC, salts used to prepare oral, gastric and intestinal electrolyte solutions, Nile red and dimethyl sulfoxide (DMSO) were purchased from Sigma-Aldrich (MO, USA). Tween ${ }^{\circledR} 80$ was obtained from Panreac (Spain), sodium hydroxide was purchased from JMGS (Portugal) and hydrochloric acid was obtained from CHEM-LAB (Belgium). Acetonitrile and chloroform were obtained from Fisher Scientific (NJ, USA). Dulbecco's modified Eagle's medium (DMEM), non-essential amino acids (NEAA), phosphate buffered saline (PBS), Hanks' Balanced Salt Solution (HBSS) were obtained from Lonza (Switzerland), penicillin/streptomycin (P/S) were purchased from Sigma-Aldrich (MO, USA), fetal bovine serum (FBS) was obtained from Merck (Germany), trypsin/EDTA was purchased from Invitrogen (Paisley, UK) and 3-(4,5-dimethylthiazol-2-yl)-5(3-carboxymethonyphenol)-2-(4-sulfophenyl)-2H-tetrazolium (MTS) were obtained from Promega (Madison, EUA). Tissue culture plate inserts (12 wells, $0.4 \mu \mathrm{m}$ pore size, polycarbonate membrane, $1.12 \mathrm{~cm}^{2}$ ) were purchase from VWR Collection (VWR International, Portugal). Caco-2 cell line was purchased from Deutsche Sammlung von Microorganismen und Zellkulturen (Braunschweig, Germany).

\subsection{SLN production}

SLN were prepared according to Kheradmandnia, Vasheghanifarahani, Nosrati, and Atyabi (2010) with some modifications. Different formulations have been tested (Table 1, Supplementary File) and the formulation used was selected based on the results of the droplet's size, PDI and stability (results not shown). Beeswax (3\%), PHOSPHOLIPON $® 90 \mathrm{G}$ (lecithin) (1.5\%) and curcumin (0.1\%) were melted on a water bath at $80{ }^{\circ} \mathrm{C}$. Tween ${ }^{\circledR} 80(1.5 \%)$ was solubilized in distilled water at $80^{\circ} \mathrm{C}$ in an Ultra-Turrax homogenizer (T18, Ika-Werke, Germany) during $2 \mathrm{~min}$ at 3,400 rpm. The aqueous solution was added to the lipid solution and mixed on an Ultra-Turrax homogenizer (T18, Ika-Werke, Germany) at 18,000 rpm during $8 \mathrm{~min}$. Then, the resulting nanoemulsion was gradually dispersed at a volume ratio of 1:10 in cold water at $2{ }^{\circ} \mathrm{C}$ under stirring at 2,000 rpm. The SLN solution was stored at $4{ }^{\circ} \mathrm{C}$ under dark conditions.

\subsection{NLC production}

NLC were produced through high-speed homogenization and ultrasonication as reported by Aditya et al. (2013), with some modifications. Different formulations have been tested (Table 1, Supplementary File) and the formulation used was selected based on the results of the droplet's size, PDI and stability (results not shown). Lipid phase, formed by curcumin $(0.1 \%)$, PHOSPHOLIPON ${ }^{\circledR}$ 90G (lecithin) (1.5\%), MCTs $(2.5 \%)$ and beeswax $(2.5 \%)$, was melted at $75{ }^{\circ} \mathrm{C}$. Tween ${ }^{\circledR} 80(1.5 \%)$ and distilled water were heated to $75{ }^{\circ} \mathrm{C}$ forming the aqueous phase. Then aqueous phase was quickly dispersed in the lipid phase. Both phases were homogenized using an Ultra-Turrax homogenizer (T18, IkaWerke, Germany) during $5 \mathrm{~min}$ at 3,000 rpm. The resulting emulsion was subject to ultrasonication through a probe sonicator (Vibra-cell VCX 500, Sonics, USA) for $4 \mathrm{~min}$ (work time: $4 \mathrm{~s}$; rest time: $2 \mathrm{~s}$ ). Finally, it was dispersed in cold water at $2{ }^{\circ} \mathrm{C}$ at a volume ratio of $1: 10$ under stirring at $600 \mathrm{rpm}$ for $15 \mathrm{~min}$. The NLC solution was stored at $4{ }^{\circ} \mathrm{C}$ under dark conditions.

\subsection{NE production}

NE were prepared through high pressure homogenization according to other authors (Pinheiro, Coimbra, \& Vicente, 2016). Different formulations have been tested (Table 1, Supplementary File) and the formulation used was selected based on the results of the droplet's size, PDI and stability (results not shown). The lipid phase was composed by MCTs and curcumin $(0.1 \%)$ and the aqueous phase by PHOSPHOLI$\mathrm{PON}{ }^{\circledR} 80 \mathrm{H}$ (lecithin) (2.5\%) and distilled water. Both phases were homogenized at a volume ratio of 1:9 at room temperature. First, both solutions were pre-mixed using an Ultra-Turrax homogenizer (T18, IkaWerke, Germany) during $2 \mathrm{~min}$ and thereafter, the resulting emulsion was passed through a high-pressure homogenizer (NanoDeBee, Bee International, Massachusetts, USA) at 20,000 psi (137.9 MPa) during 20 cycles. The NE solution was stored at $4{ }^{\circ} \mathrm{C}$ under dark conditions. 


\subsection{In vitro digestion}

All nanostructures were subjected to an in vitro digestion process using the harmonized static in vitro digestion model described by Minekus et al. (2014). This model simulates the mouth, stomach and intestinal phases. In the oral phase, simulated salivary fluid (SSF) ( $\mathrm{KCl}$ $15.1 \mathrm{mM}, \mathrm{KH}_{2} \mathrm{PO}_{4} 3.7 \mathrm{mM}, \mathrm{NaHCO}_{3} 13.6 \mathrm{mM}, \mathrm{MgCl}_{2}\left(\mathrm{H}_{2} \mathrm{O}\right)_{6} 0.15 \mathrm{mM}$, $\left(\mathrm{NH}_{4}\right)_{2} \mathrm{CO}_{3} 0.06 \mathrm{mM}$ and $\mathrm{HCl} 1.1 \mathrm{mM}$ ), $\mathrm{CaCl}_{2}\left(\mathrm{H}_{2} \mathrm{O}\right)_{2} 0.3 \mathrm{M}$ (in order to achieve $0.75 \mathrm{mM}$ at the final mixture) and Milli-Q water (in order to make up the final volume) were added to $5 \mathrm{~mL}$ of sample. The mixture was incubated at $37^{\circ} \mathrm{C}$ for 2 min under orbital agitation at $120 \mathrm{rpm}$. $\alpha$-amylase was not used as samples did not contain starch (Sarkar, Goh, $\&$ Singh, 2009). In gastric phase, simulated gastric fluid (SGF) ( $\mathrm{KCl} 6.9$ $\mathrm{mM}, \mathrm{KH}_{2} \mathrm{PO}_{4} 0.9 \mathrm{mM}, \mathrm{NaHCO}_{3} 25 \mathrm{mM}, \mathrm{NaCl} 47.2 \mathrm{mM}, \mathrm{MgCl}_{2}\left(\mathrm{H}_{2} \mathrm{O}\right)_{6}$ $0.12 \mathrm{mM},\left(\mathrm{NH}_{4}\right)_{2} \mathrm{CO}_{3} 0.5 \mathrm{mM}$ and $\mathrm{HCl} 15.6 \mathrm{mM}$ ), $\mathrm{CaCl}_{2}\left(\mathrm{H}_{2} \mathrm{O}\right)_{2} 0.3 \mathrm{M}$ (in order to achieve $0.075 \mathrm{mM}$ at the final mixture) and pepsin solution (with final activity of $2,000 \mathrm{U} / \mathrm{mL}$ in the final mixture) were added to the previous mixture. The $\mathrm{pH}$ was adjusted to 3.0 with $\mathrm{HCl} 1 \mathrm{M}$ and Milli-Q water was added to make up the final volume. The samples were incubated for $2 \mathrm{~h}$ at $37^{\circ} \mathrm{C}$ under orbital agitation at $120 \mathrm{rpm}$. Finally, the intestinal phase consisted of simulated intestinal fluid (SIF) (KCl 6.8 $\mathrm{mM}, \mathrm{KH}_{2} \mathrm{PO}_{4} 0.8 \mathrm{mM}, \mathrm{NaHCO}_{3} 85 \mathrm{mM}, \mathrm{NaCl} 38.4 \mathrm{mM}, \mathrm{MgCl}_{2}\left(\mathrm{H}_{2} \mathrm{O}\right)_{6}$ $0.33 \mathrm{mM}$ and $\mathrm{HCl} 8.4 \mathrm{mM}$ ), $\mathrm{CaCl}_{2}\left(\mathrm{H}_{2} \mathrm{O}\right)_{2} 0.3 \mathrm{M}$ (in order to achieve 0.3 $\mathrm{mM}$ at the final mixture), bile salts (in order to achieve $10 \mathrm{mM}$ at the final mixture) and pancreatin solution (with final activity of $100 \mathrm{U} / \mathrm{mL}$ in the final mixture). The $\mathrm{pH}$ was adjusted to 7.0 with $\mathrm{NaOH} 1 \mathrm{M}$ or $\mathrm{HCl}$ $1 \mathrm{M}$ and then Milli-Q water was added to achieve the final volume. The samples were incubated during $2 \mathrm{~h}$ at $37{ }^{\circ} \mathrm{C}$ under orbital agitation at $120 \mathrm{rpm}$. After each phase, samples were collected. For microscopy analysis, the gastric phase reaction (i.e. pepsin activity) was stopped by increasing the $\mathrm{pH}$ to 7.0 using $\mathrm{NaOH} 1 \mathrm{M}$ and placing the samples in an ice bath, while for particle's size analysis, which was carried out immediately after gastric phase, the samples were placed in an ice bath. After full digestion, the reaction was stopped adding enzyme inhibitor Pefabloc ${ }^{\circledR}(1 \mathrm{mM})(10 \mu \mathrm{L}$ for each $1 \mathrm{~mL}$ of sample). All the samples were tested at least in triplicate.

\subsection{Nanostructures' particle size and $\zeta$-potential}

Nanostructures' particle size, polydispersity index (PDI) and $\zeta$-potential were measured in each digestion process phase using dynamic light scattering (DLS) (Zetasizer Nano SZ, Malvern, Worcestershire, UK). All samples were diluted at 1:100 with a buffer solution of the same $\mathrm{pH}$ of the samples.

\subsection{Curcumin's bioaccessibility and stability}

Curcumin bioaccessibility was assumed as the curcumin fraction present inside the micelle phase, while stability was assumed as the nontransformed curcumin fraction present in the whole digesta at the end of the digestion. Curcumin bioaccessibility and stability have been determined at the end of the digestion based on the methodology described by Liu, Wang, McClements, and Zou (2018) with some modifications. The digesta $(10 \mathrm{~mL})$ was centrifuged (Allegra 64R, Beckman Coulter Inc., USA) at $18,700 \mathrm{~g}$ at room temperature for $30 \mathrm{~min}$, and the supernatant (which was assumed as the micelle phase) was collected. Digesta or micelle phase samples $(5 \mathrm{~mL}$ ) were mixed with $5 \mathrm{~mL}$ of chloroform using a vortex and centrifuged at $700 \mathrm{~g}$ at room temperature for $10 \mathrm{~min}$. The bottom layer was collected, and the top layer was subjected again to the extraction procedure. The second bottom layer was combined with the first one and analyzed in an UV-VIS spectrophotometer (V-560, Jasco, USA) at $420 \mathrm{~nm}$. Curcumin concentration was determined through a calibration curve (absorbance versus curcumin concentration) in chloroform.

Curcumin bioaccessibility $(B)$, stability $(S)$ and effective bioavailability (BA) were calculated using Eqs. (1)-(3) (respectively) (Liu et al.,
2018), as shown below:

$B=\frac{C_{\text {Micelle }}}{C_{\text {Digesta }}} \times 100$

$S=\frac{C_{\text {Digesta }}}{C_{\text {Initial }}} \times 100$

$B A=B \times S$

where $C_{\text {micelle }}$ and $C_{\text {Digesta }}$ are the curcumin concentrations measured at the end of the digestion in micellar phase and digesta, respectively. $C_{\text {initial }}$ is the curcumin concentration present in the nanostructures at the beginning of digestion process, which is the same for all nanostructures. The effective bioavailability is a curcumin absorption estimative; however, this value must be analyzed with precaution, once there are other factors that influence curcumin absorption which were not considered, such as absorption and metabolism (Zou et al., 2016).

\subsection{Free fatty acids release}

Free fatty acids (FFA) release was the method used to measure nanostructures' digestibility. At the end of the gastric phase, the sample was mixed with all salt's solutions of the intestinal phase (Section 2.5) and the $\mathrm{pH}$ was adjusted to 7.0 with $\mathrm{HCl} 1 \mathrm{M}$ or $\mathrm{NaOH} 1 \mathrm{M}$. Then, pancreatin solution was added to the sample and $\mathrm{pH}$ was maintained at 7.0 by the addition of $0.05 \mathrm{M} \mathrm{NaOH}$ solution using an auto-titration unit (pH-stat method) (Titrando 902, Metrohm, Switzerland) during $2 \mathrm{~h}$ in a heated jacketed reactor at $37^{\circ} \mathrm{C}$ under agitation. Blank assays have been performed (i.e., digestion conducted without pancreatin) to determine the $\mathrm{NaOH}$ volume needed to achieve $\mathrm{pH}$ 7.0. The FFA released amount, \%FFA, was determined through Eq. (4) (Li, Hu, Du, Xiao, \& McClements, 2011):

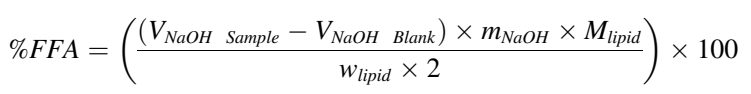

where $V_{\mathrm{NaOH} \text { sample }}$ and $V_{\mathrm{NaOH} \text { Blank }}$ are the $\mathrm{NaOH}$ titrated volume in the sample and blank assays, respectively, $m_{\mathrm{NaOH}}$ is the $\mathrm{NaOH}$ titrant molar concentration, in this case $0.05 \mathrm{M}, M_{\text {lipid }}$ is the molecular weight of MCT oil $\left(500\right.$ g.mol $\left.{ }^{-1}\right)$ and the beeswax's reference lipid (256.4 g.mol ${ }^{-1}$ for palmitic acid) and $w_{\text {lipid }}$ is the initial mass of lipid (g).

\subsection{Fluorescence microscopy}

Nanostructures' microstructure was observed using a fluorescence microscope (Olympus, BX51, Japan). The samples were stained with Nile Red $(0.25 \mathrm{mg} / \mathrm{mL}$ in DMSO) at 1:10 ratio (dye:sample, $\mathrm{v} / \mathrm{v}$ ), which enabled the oil droplets to become visible. Samples of the initial nanostructures and of each digestion process phase were analyzed. The images were captured with a 100x oil immersion objective lens.

\subsection{Cell culture and digested samples treatment}

Caco- 2 cell line was used for cytotoxicity and permeability studies. Caco-2 cells were grown in DMEM supplemented with $10 \%$ (v/v) FBS, $1 \%(\mathrm{v} / \mathrm{v})$ NEAA solution and $1 \%(\mathrm{v} / \mathrm{v}) \mathrm{P} / \mathrm{S}$. Cell cultures were grown in a humidified $5 \% \mathrm{CO}_{2}$ incubator at $37{ }^{\circ} \mathrm{C}$ and medium was changed periodically.

In order to eliminate precipitates and residues resulting from the digestive process, digested samples used on cellular assays were subjected to a filtration and centrifugation process. The mixture was transferred to Amicon ${ }^{\circledR}$ Ultra-4 Centrifugal Filter, 10 KDa (Merck Millipore, Germany) and centrifuged (Mikro 220R, Hettich, Germany) at $4,000 \mathrm{~g}$ for $40 \mathrm{~min}$. The filtrated samples were used on subsequent cellular assays. 


\subsection{Cell viability assay}

Viability assays were performed using Caco-2 cells. Cells were seeded in 96 -well culture plates at $2 \times 10^{4}$ cells/well, and the medium changed every $48 \mathrm{~h}$. The cells were allowed to grow for 5-7 d, until confluence was reached. All samples tested were diluted in DMEM culture medium with $0.5 \%$ FBS (Serra et al., 2011). The digested and non-digested nanostructures' dilutions were defined regarding the maximum curcumin's concentration present in the samples. The digested and nondigested excipients were diluted with regard to the maximum excipient concentration present in the nanostructures. Finally, gastrointestinal (GI) fluids sample was diluted with regard to the maximum curcumin concentration in non-digested nanostructures. All diluted samples were added to the wells, except the control cells wells which contained only the solvent/medium used. The incubation with the different formulations was carried out for $24 \mathrm{~h}$ in a $5 \% \mathrm{CO}_{2}$ humidified atmosphere at $37{ }^{\circ} \mathrm{C}$. The experiments were conducted in triplicate with cells between passages 40 and 45 .

Viability evaluation was performed by the colorimetric MTS assay. This assay is based on the conversion of tetrazolium salt, into a colored formazan product, by mitochondrial activity of viable cells at $37{ }^{\circ} \mathrm{C}$. The viability reagent was diluted according to the manufacturer information, $16 \%(\mathrm{v} / \mathrm{v})$ of MTS in cell culture media (DMEM supplemented with $0.5 \% \mathrm{FBS})$. Following the incubation period $\left(24 \mathrm{~h}\right.$ at $37^{\circ} \mathrm{C}$ in a $5 \% \mathrm{CO}_{2}$ humidified atmosphere) samples were removed, cells were rinsed with PBS and $100 \mu \mathrm{L}$ MTS was added to each well, reacting for $3 \mathrm{~h}$ at $37^{\circ} \mathrm{C}$ in a $5 \% \mathrm{CO}_{2}$ humidified atmosphere. The quantity of formazan produced was measured in a spectrophotometer (EPOCH, 219 Bio-Tek, USA) at $490 \mathrm{~nm}$ and is directly proportional to the number of living cells in culture. The results were expressed as percentage (\%) of cell viability relative to the control (i.e. untreated cells in DMEM medium). The plates were also examined under the microscope to assess the degree of cell survival (Serra et al., 2011).

\subsection{Curcumin permeability studies}

Curcumin permeability studies were carried out based on Silva et al. (2019), with some modifications. Caco-2 cells were cultured at $1 \times 10^{5}$ cells/well on 12-well cell culture plate inserts for 18-21 d. The culture medium was changed three times a week. The cell monolayer's development and integrity were controlled two to three times a week by the transepithelial electrical resistance (TEER) measurements using an epithelial Volt-Ohm-meter (Millipore Millicell ERS-2, Massachusetts, USA). On the day of the experiment, the culture medium was removed; the cells were washed twice with $200 \mu \mathrm{L}$ of HBSS and incubated during $15 \mathrm{~min}$ at $37{ }^{\circ} \mathrm{C}$ in $5 \% \mathrm{CO}_{2}$ with $200 \mu \mathrm{L}$ HBSS solution (transporter buffer). For the permeability experiment, $0.5 \mathrm{~mL}$ of nanostructures (i.e. SLN, NLC and NE) or free curcumin diluted with HBSS at $25 \mu \mathrm{g} \cdot \mathrm{mL}^{-1}$ of curcumin were added to the apical side. In order to maintain well conditions, $1.5 \mathrm{~mL}$ of HBSS with $1 \%$ of Tween ${ }^{8} 80$ was added to the basolateral side (Silva et al., 2017). At defined times (0, 15, 30, 45, 60, 120,180 and $240 \mathrm{~min}$ ), basolateral samples were collected. All samples were frozen until curcumin's determination through HPLC-FL as described in Section 2.13 (Silva et al., 2019).

The apparent permeability coefficients $\left(P_{a p p}\right)$ of curcumin were determined using the following expression (Eq. (5)):

$P_{a p p}=\frac{\frac{d Q}{d t}}{C_{0} \times A}$

where $d Q / d t$ is the cumulative transport rate $\left(\mu \mathrm{g} \cdot \mathrm{min}^{-1}\right.$ ) across the monolayer established as the slope obtained by the linear regression of cumulative transported amount as a function of time, $C_{O}$ is the initial curcumin concentration ( $\mu \mathrm{g} \cdot \mathrm{mL}^{-1}$ ) in the apical compartment and $A$ is the surface area of the membrane $\left(1.12 \mathrm{~cm}^{2}\right)$.

\subsection{HPLC analysis of curcumin}

The curcumin concentration was determined based on the methodology described by Silva et al. (2019). The samples were diluted in acetonitrile at a volume ratio of $1: 1$ and centrifuged during $15 \mathrm{~min}$ at $14,000 \mathrm{rpm}$. After that, the supernatant was collected and injected in the HPLC system. The HPLC system was composed by a Varian Prostar 210 pump, a Varian Prostar 410 autosampler and a Jasco FP-920 fluorescence detector $\left(\lambda_{\text {exc }}=420 \mathrm{~nm}\right.$ and $\left.\lambda_{e m}=540 \mathrm{~nm}\right)$. A Varian 850-MIB data system interface and a Galaxie chromatography data system were used to manage the instrument and the chromatographic data, respectively. The HPLC separation was carried out on a C18 reverse-phase YMC-Pack ODS-AQ analytical column $(250 \times 4.6 \mathrm{~mm}$ I.D., $5 \mu \mathrm{m})$, which was fitted with a pre-column with the same stationary phase. The mobile phase consisted in a mixture of aqueous acetic acid $(2 \% \mathrm{v} / \mathrm{v})$ at pH 2.5 and acetonitrile at a volume ratio of 47:53, which was filtered and degassed with a $0.22 \mu \mathrm{m}$ nylon membrane filter (GHP, Gelman). The compounds were eluted at a flow rate of $1.0 \mathrm{~mL} \cdot \mathrm{min}^{-1}$ during a $15 \mathrm{~min}$ isocratic run at $25{ }^{\circ} \mathrm{C}$ and the injection volume was $50 \mu \mathrm{L}$. The calibration curve was performed using standard solutions with concentrations between $0.1 \mu \mathrm{g} \cdot \mathrm{mL}^{-1}$ and $10 \mu \mathrm{g} \cdot \mathrm{mL}^{-1}$ of curcumin (Sigma-Aldrich (MO, USA)) in acetonitrile. The retention times of bisdemethoxycurcumin, demethoxycurcumin and curcumin, were $10 \mathrm{~min}, 11 \mathrm{~min}$ and $12 \mathrm{~min}$, respectively. Their quantification was performed through the comparison between the peak's areas obtained and the calibration curve.

\subsection{Statistical analyses}

The assays were performed at least in triplicate and presented as mean \pm standard deviation (SD). Statistical analysis was carried out using OriginPro 2018 Statistic software (version b9.5.1.195; OriginLab Corporation, Northampton, USA). Data were analyzed using one-way analysis of variance (ANOVA) and Tukey's test was used to evaluate significant differences between the mean values $(p<0.05)$.

\section{Results and discussion}

\subsection{Nanostructures' characterization}

The nanostructures were produced with different techniques, namely NE were produced by high pressure homogenization, NLC by high speed homogenization and ultrasonication and SLN by high speed homogenization. All ingredients used to produce all nanostructures were biobased and/or GRAS.

The particle size, PDI and $\zeta$-potential of all nanostructures are presented in Table 1. NE and SLN presented similar particle sizes (between $140 \mathrm{~nm}$ and $150 \mathrm{~nm}$ ), while NLC' size was significantly higher $(p<$ 0.05 ), $164.4 \pm 10.27 \mathrm{~nm}$, showing that the lipid physical state (liquid $v s$ solid) had no significant effect on particle size. However, for NLC, the liquid lipid proportion in the liquid/solid mixture could have a high influence in this parameter. Similarly, de Souza, Saez, de Campos, and Mansur (2019) showed that when MCT proportion was reduced from three to two parts per one part of solid lipid, the NLC produced presented an increase of particle's size. Furthermore, other authors reported that

Table 1

Particle size, polydispersity index (PDI) and $\zeta$-potential of curcumin loaded NE, NLC and SLN.

\begin{tabular}{llll}
\hline Structure & z-average diameter $(\mathrm{nm})$ & PDI & $\zeta$-Potential $(\mathrm{mV})$ \\
\hline NE & $146.0 \pm 8.8^{\mathrm{a}}$ & $0.233 \pm 0.023^{\mathrm{a}}$ & $-32.5 \pm 2.0^{\mathrm{a}}$ \\
SLN & $145.4 \pm 8.1^{\mathrm{a}}$ & $0.253 \pm 0.010^{\mathrm{b}}$ & $-23.6 \pm 1.3^{\mathrm{b}}$ \\
NLC & $164.4 \pm 10.6^{\mathrm{b}}$ & $0.108 \pm 0.015^{\mathrm{c}}$ & $-11.2 \pm 1.3^{\mathrm{c}}$ \\
\hline
\end{tabular}

$\mathrm{XXX}^{\mathrm{a}-\mathrm{c}}$ Mean values with different superscript letters within the same column are significantly different from each other $(\mathrm{p}<0.05)$. 
the incorporation of liquid oil in the production of NLC can increase the particle size due to interfacial tension increase, nanoparticles swollen core increase or core-shell type nanoparticles production (Tamjidi, Shahedi, Varshosaz, \& Nasirpour, 2014).

According to the results, all nanostructures showed PDI values lower than 0.3 and particle size below $200 \mathrm{~nm}$, being suitable for oral delivery (Swarnakar, Venkatesan, \& Betageri, 2019). NLC presented the lowest PDI value comparing to NE and SLN $(0.108,0.233$ and 0.253 , respectively) ( $p<0.05)$. However, all nanostructures showed a narrow distribution size (PDI $<0.3$ ), (Table 1 ). These differences were probably caused by the technique used to produce each type of nanostructure, showing that high-speed homogenization produce samples with higher PDI values than ultrasonication processes. de Souza et al. (2019) tested different types of techniques to produce NLC and showed that the nanoparticles produced using high-speed homogenization presented higher PDI values than those produced using ultrasonication. Together with the technique used, the emulsifier composition and their concentration could also have influence on the particle's size and PDI of the nanostructures, as observed by other authors (El Kinawy, Petersen, Bergt, \& Ulrich, 2013; Ma et al., 2018).

Regarding $\zeta$-potential, it is possible to observe that all nanostructures presented negative values, with $\mathrm{NE}$ showing the lowest negative value and NLC the highest one: $-32.5 \mathrm{mV}$ and $-11.2 \mathrm{mV}$, respectively (Table 1). Usually, a nanosuspension is considered physically stable when the $\zeta$-potential value is around $\pm 30 \mathrm{mV}$ and stabilized only by electrostatic repulsion. However, when a combined electrostatic and steric stabilization exists, it is required a lower $\zeta$-potential, around \pm 20 $\mathrm{mV}$ (Tamjidi et al., 2014). In case of SLN and NLC, their stabilization is a combination of electrostatic forces due to the presence of lecithin and steric-related forces due to Tween ${ }^{\circledR} 80$. Other authors also reported SLN and NLC $\zeta$-potential values $<-20 \mathrm{mV}$, using lecithin and Tween ${ }^{\circledR} 80$ as emulsifiers (Soleimanian, Goli, Varshosaz, \& Sahafi, 2018). Furthermore, the difference of $\zeta$-potential between SLN and NLC can be due to the ratio of lipids and emulsifiers' concentration. Despite both nanostructures have the same emulsifier composition and concentration, SLN has a lower lipids' concentration than NLC. Thus, SLN has more emulsifier to cover the lipid droplets, which resulted in an increase of the $\zeta$-potential negative value.

\subsection{In vitro digestion}

\subsubsection{Size, $\zeta$-potential and morphology}

Particle size and $\zeta$-potential have been determined throughout the digestion process. Fig. 1 presents the $\zeta$-potential of curcumin-loaded nanostructures (i.e. NE, SLN and NLC) (Fig. 1A) and their z-average diameter (Fig. 1B) before digestion (initial) and after each simulated digestion process phase (namely, oral, gastric and intestinal phases). As discussed previously, before digestion, NE, SLN and NLC showed negative $\zeta$-potential values. When the nanostructures were subjected to the simulated oral conditions, NE maintained their surface charge, while SLN and NLC showed a slight, but significant $(p<0.05)$, decrease of $\zeta$-potential values. This could be due to the electrostatic screening effects between lipid particles and salt ions present in the simulated salivary fluid (Chang \& McClements, 2016). Under simulated gastric conditions, all nanostructures presented a positive surface charge, ranging between $13.2 \pm 0.60 \mathrm{mV}$ and $4.2 \pm 0.56 \mathrm{mV}$, where $\mathrm{NE}$ had the highest $\zeta$-potential value $(p<0.05)$. The high ionic strength, low $\mathrm{pH}$ and ionic species present in the gastric phase can promote changes in the interfacial surface of lipid particles. However, when the nanostructures pass to the intestinal phase, $\zeta$-potential values were negative and close to the initial $\zeta$-potential values. This may be due to the neutral $\mathrm{pH}$ found in this phase, the adsorption of lipase and anionic species (i.e. phospholipids and bile salts present in the simulated intestinal fluid) to the nanostructures' surface and fatty acids production by lipid digestion (Park, Garcia, Shin, \& Kim, 2017).

During in vitro digestion, it seems that all nanostructures are stable at the oral phase; however, at the end of the gastric phase, they showed some instability $(p<0.05)$, where NE showed the highest particle size increase from $125.5 \pm 14.17 \mathrm{~nm}$ to $1605.7 \pm 164.4 \mathrm{~nm}(p<0.05)$ (Fig. 1B). In fact, the NE fluorescent images showed that some coalescence had occurred during the gastric phase (Fig. 2). The changes at lipid droplets' interfacial surface (showed by $\zeta$-potential results) could have decreased the repulsion between lipid droplets and promoted aggregation through coalescence, resulting in a size increase. Ozturk, Argin, Ozilgen, and McClements (2014) also showed that lecithin NE exhibited some instability when subjected to high ionic strength and low pH. Similarly, other authors demonstrated that lecithin NE particle size increased after the gastric phase (Chang \& McClements, 2016; Shu et al., 2018). Regarding SLN and NLC, both presented a particle size increase $(p>0.05)$ after the gastric phase from $145.3 \pm 4.64 \mathrm{~nm}$ to $489.1 \pm$ $215.11 \mathrm{~nm}$ and from $173.3 \pm 7.52 \mathrm{~nm}$ to $524.5 \pm 168.2 \mathrm{~nm}$, respectively. These results may be explained by destabilization of forces exerted on the lipid particles due to the presence of lecithin and Tween ${ }^{\circledR}$ 80. The electrostatic force is annulled due to the low $\mathrm{pH}$ and high ionic strength, while the steric force is not strong enough to maintain the repulsion between particles, causing some aggregation as can be seen on Fig. 2 (Zimmermann \& Müller, 2001). After $2 \mathrm{~h}$ of intestinal phase, all nanostructures presented a slight particle size increase, but not significant $(p>0.05)$. NE presented a higher particle size increase than SLN and NLC during in vitro digestion process. Thus, nanostructures composed only by liquid lipids (e.g. NE) seems to be more unstable under digestion than the nanostructures which have solid lipids in their
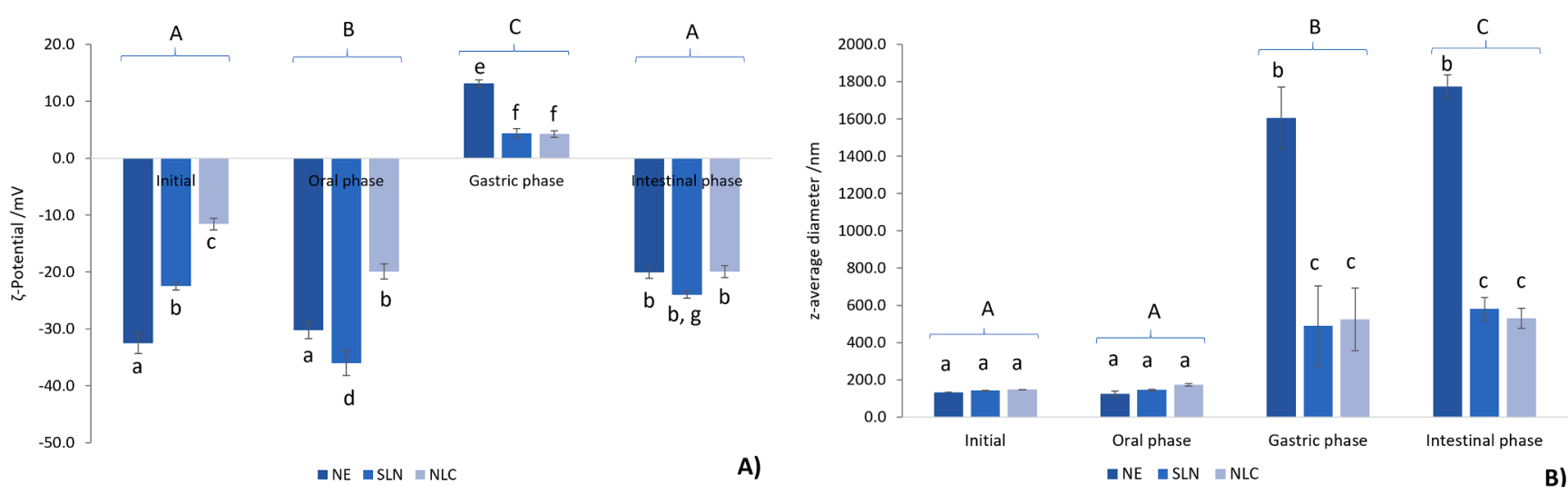

Fig. 1. $\zeta$-potential (A) and particle size (B) of nanostructures (NE, SLN and NLC) in different in vitro gastrointestinal digestion phases. Error bars represent the standard deviation of $n=3$ replicates. ${ }^{\text {A-C }}$ Different capital letters indicate significant difference between simulated gastrointestinal phases. ${ }^{\mathrm{a}-\mathrm{g}} \mathrm{Different}$ lower-case letters indicate significant difference between nanostructures/phase interactions $(p<0.05)$. 


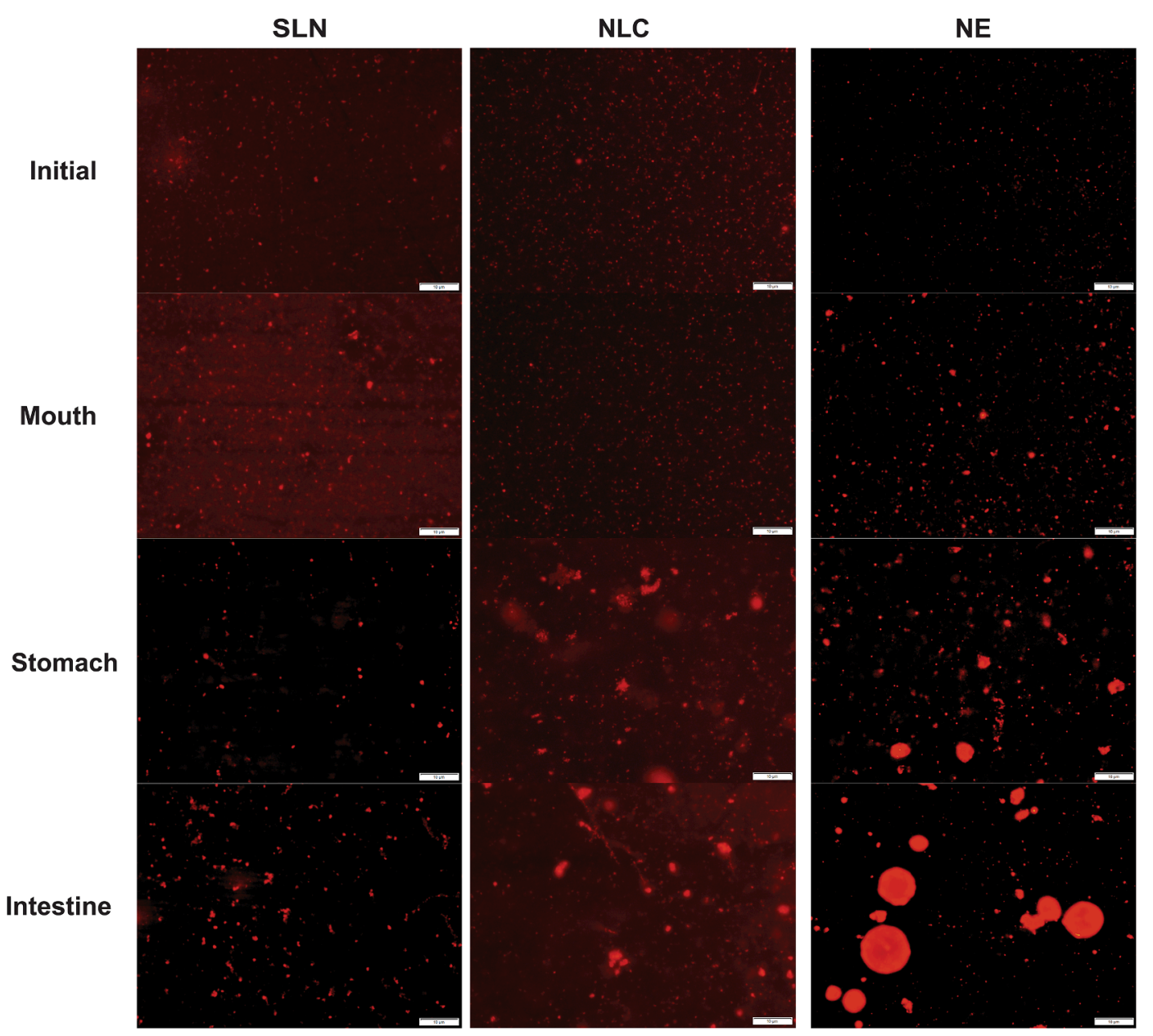

Fig. 2. Fluorescence microscopy images of nanostructures (SLN, NLC and NE) after each in vitro gastrointestinal digestion phase. The scale bar for all images is $10 \mu \mathrm{m}$.

lipid phase composition. Also, the nanostructures' emulsifier composition (lecithin for NE and lecithin + Tween $80 \circledR$ for NLC and SLN) could have influenced their behavior under digestion.

\subsubsection{FFA release}

During in vitro intestinal phase digestion, all nanostructures presented a fast FFA's concentration increase (a burst release) on the first minutes and then a more gradual concentration increase on the remaining time (data not shown). At the end of in vitro digestion, $\mathrm{NE}$ presented a lower FFA percentage than SLN, $40.7 \pm 2.98 \%, 53.4 \pm$ $2.44 \%$, respectively ( $p<0.05$ ), Fig. 3. Although liquid particles' (i.e. $\mathrm{NE}$ ) surface promotes an easier access and better bile and lipase

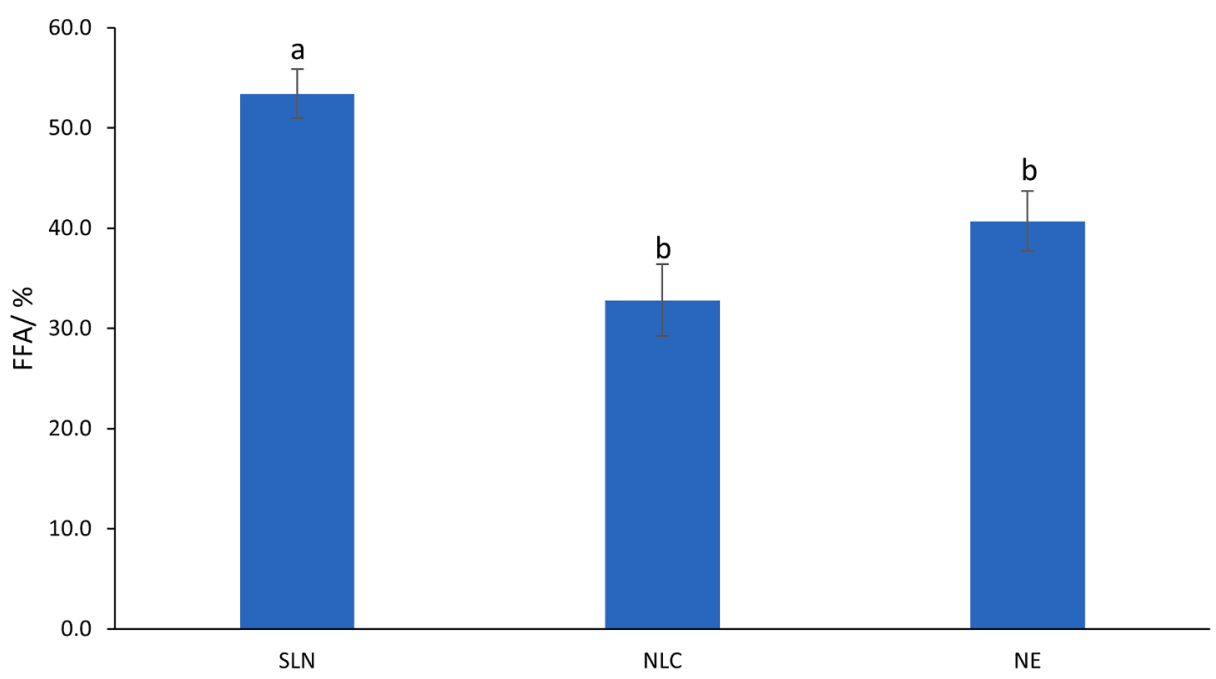

Fig. 3. Percentage of FFA released after in vitro digestion from curcumin-loaded SLN, NLC and NE. Error bars represent the standard deviation of $n=3$ replications. Different letters indicates significant difference between nanostructures $(p<0.05)$. 
adsorption than solid particle surface (i.e. SLN), promoting a higher lipolysis rate and degree (Bonnaire et al., 2008), the particle's size instability observed in $\mathrm{NE}$ at the end of the gastric phase, may explain these results, once the increase of the particle's size reduces the surface area for lipase adsorption reducing the lipid digestion. NLC presented the lowest FFA percentage, $32.8 \pm 3.58 \%$, which can indicate that the combination of liquid and solid lipids can cause a higher resistance to the lipase's adsorption and hydrolysis. Bonnaire et al. (2008) reported that, besides the influence of lipid physical state on lipase adsorption to the droplet surface, where typically liquid lipids promote a better lipase's adsorption than the solid lipids, the spatial organization of lipid molecules can influence lipase ability to hydrolyze the triacylglycerols, once the triglycerides crystals can present different polymorphs, namely the $\beta$-form which is the densest polymorphic form (Himawan, Starov, \& Stapley, 2006). Other authors observed that, besides the lipid's physical state, the chain length of the fatty acids in the lipid composition has a high impact in the FFA release and therefore in the lipid digestion degree (Helena de Abreu-Martins, Artiga-Artigas, Hilsdorf Piccoli, Martín-Belloso, \& Salvia-Trujillo, 2020).

The presented results showed that the lipid digestion degree can be affected by the stability of nanostructures under digestion (e.g. particle size) as well as the lipid composition and physical state.

\subsubsection{Bioaccessibility, stability and effective bioavailability}

At the end of the in vitro digestion process, nanostructures' bioaccessibility and stability were measured and effective bioavailability was calculated using the bioaccessibility and stability values. Fig. 4 depicts the effect of the different nanostructures in curcumin's bioaccessibility, stability and consequently, effective bioavailability. Generally, NE presented the highest values for all analyzed parameters, followed by NLC and SLN ( $p<0.05$ ). The curcumin's stability was 62.8 $\pm 5.85 \%$ for NE, $46.4 \pm 3.28 \%$ for NLC and $29.3 \pm 1.39 \%$ for SLN, showing that the presence of liquid lipid in the nanostructure's composition promoted curcumin's protection. The higher curcumin's stability observed in NE can be due to the fact of curcumin remained solubilized in the oil phase regardless of the particle stability and lipid digestion. Relatively to the lower stability observed in SLN, this can be caused by the expulsion of the bioactive compound from the fat crystals, increasing their concentration at the surface of the SLN and, therefore, the bioactive compound is more susceptible to degradation (Qian, Decker, Xiao, \& McClements, 2013). Although SLN and NLC are proposed to promote the bioactive compound's stability when compared to NE, the bioactive compounds' stability depends on different factors, such as its affinity to the solid lipid, the location where is incorporated in the particle and the type of the bonds between the bioactive compound and the particle.

NE also exhibited higher bioaccessibility $(71.7 \pm 6.18 \%)$ than NLC and SLN, $(63.7 \pm 3.58 \%$ and $53.3 \pm 3.70 \%$, respectively $)(p<0.05)$. These results may be associated to the lipid's physical state. NE presented the highest curcumin bioaccessibility, indicating that curcumin was effectively incorporated within the mixed micelles formed by FFA released, bile salts and phospholipids. On the other hand, curcumin bioaccessibility obtained for NLC was higher than the one observed for SLN, despite SLN presented higher FFA released than NLC. This can be due to fatty acid composition and fat content differences observed in the formulations, since NLC have in their composition a liquid oil whose digestion products can promote a higher incorporation of curcumin in the mixed micelles, increasing its bioaccessibility. SLN presented the lowest bioaccessibility probably due to the composition of the mixed micelles produced and their solubilization capacity. Helena de AbreuMartins et al. (2020) studied the lipolysis kinetics, micelle fraction composition and the $\beta$-carotene bioaccessibility of SLN with different solid lipids and observed that besides the lipid digestion extent, the mixed micelles composition has a high impact on the $\beta$-carotene bioaccessibility. Also, the results from the present work are in accordance with other studies that reported that bioactive compounds loaded on particles produced with liquid lipids showed higher bioaccessibility than particles produced with solid lipids (Aditya et al., 2014).

\subsection{Cellular studies}

The effect of digested and non-digested curcumin-loaded NE, SLN and NLC, as well as their excipients (before and after in vitro digestion), on cell viability was determined. The range of curcumin concentrations selected to perform the viability assays of digested curcumin-loaded nanostructures were based on the curcumin concentration detected after in vitro digestion assay. All non-digested nanostructures presented no cytotoxic effects at the highest curcumin's concentration tested, 40 $\mu \mathrm{g} \cdot \mathrm{mL}^{-1}$ of curcumin (data not shown). Regarding digested nanostructures, SLN were not cytotoxic to cells at the highest curcumin's concentration tested (i.e. $3.4 \mu \mathrm{g} \cdot \mathrm{mL}^{-1}$ curcumin) as can be seen on Fig. 5a. However, the cell viability decreased around $2.0 \mu \mathrm{g} \cdot \mathrm{mL}^{-1}$

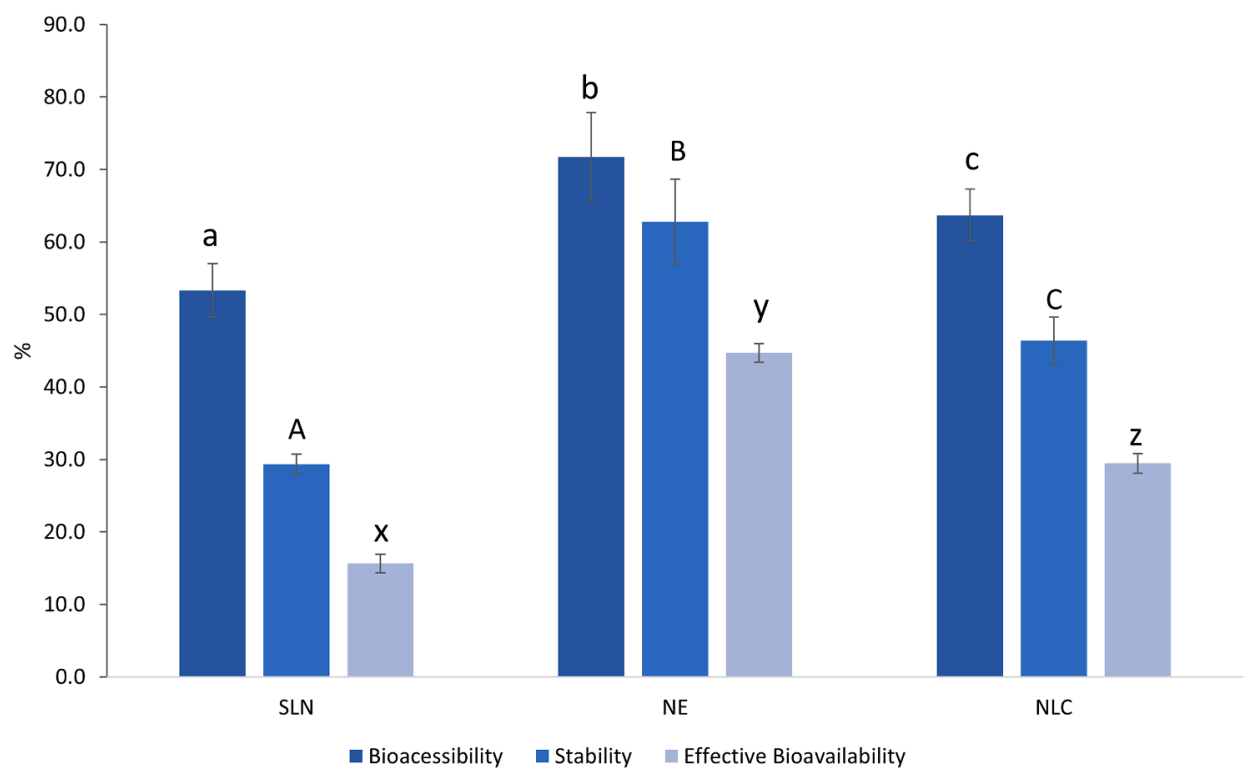

Fig. 4. Bioaccessibility, stability and effective bioavailability of curcumin loaded in SLN, NE and NLC after in vitro digestion process. Error bars represent the standard deviation of $n=6$ replications. Different letters indicates significant differences between nanostructures in each parameter $(p<0.05)$. 

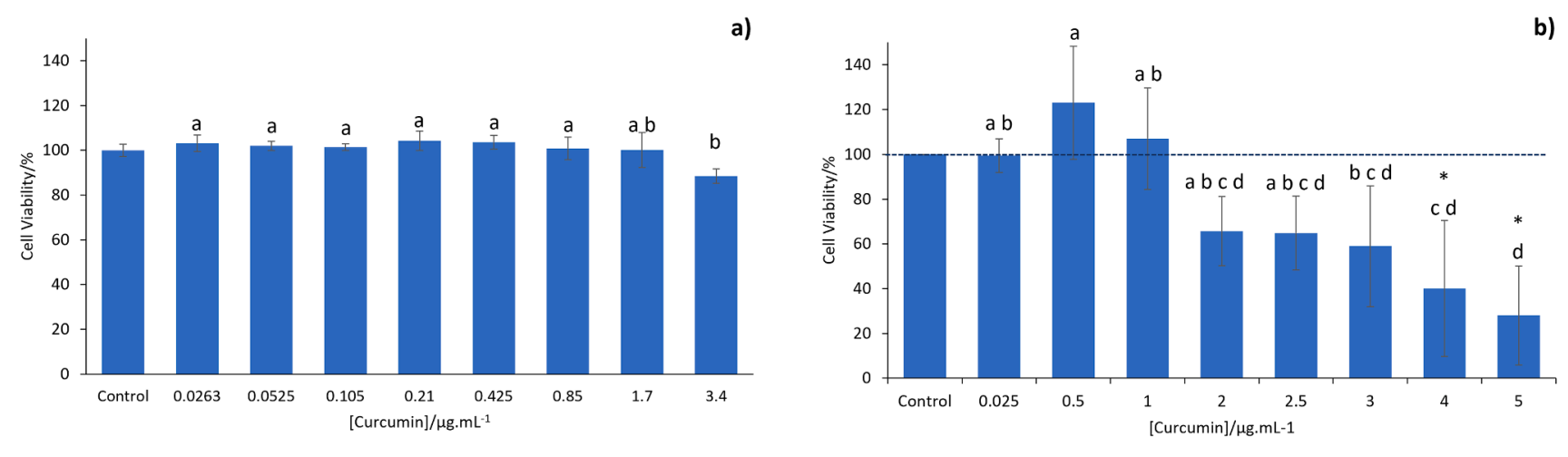

b)
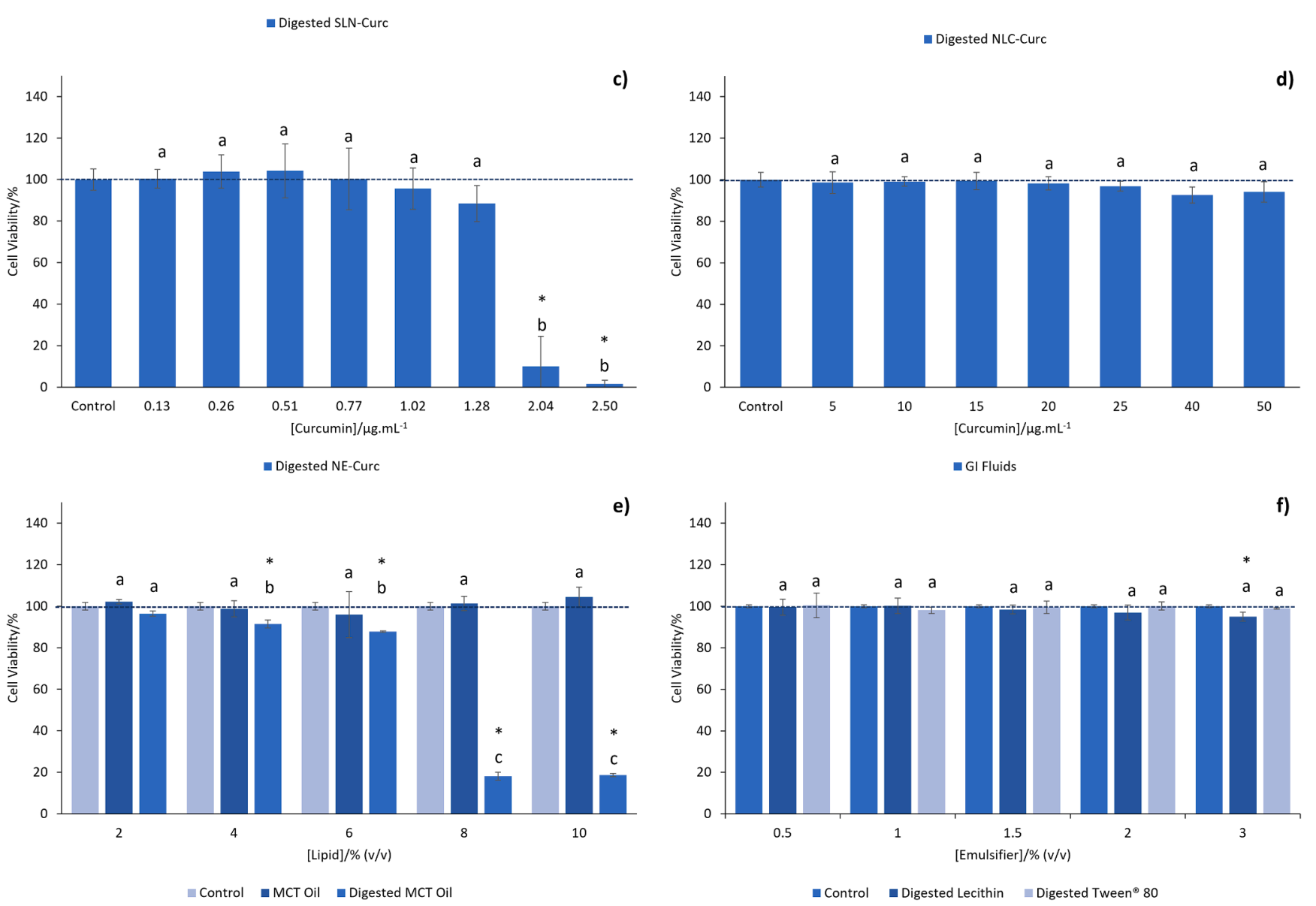

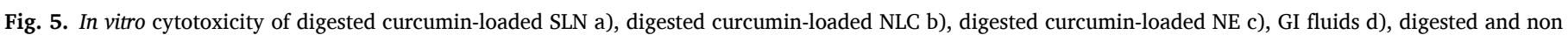

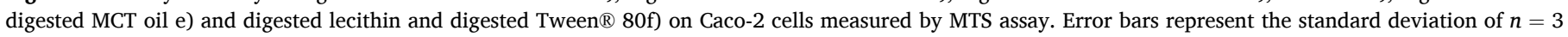

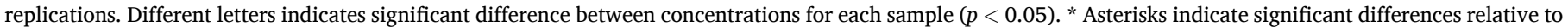
the control group $(p<0.05)$.

curcumin (Fig. 5b and c) when cells were treated with digested NLC and NE. In order to understand if the differences observed on viability results were influenced by GI fluids, these fluids were also tested. GI fluids had no effect on cell viability of digested samples at all concentrations tested (Fig. 5d). Furthermore, all excipients presented no cytotoxic effects at the highest excipient's concentration tested (i.e. $3 \%$ for the emulsifiers and $10 \%$ for the lipids) before in vitro digestion (data not shown). However, digested MCT oil decreased cell viability when included at a level of $8 \%$ lipids (Fig. 5e). On the other hand, lecithin and Tween ${ }^{\circledR} 80$ did not show cytotoxic effects at all concentrations tested after in vitro digestion (Fig. 5f). These results indicate that MCT oil digestion products were possibly the responsible for digested NE and NLC cytotoxicity effects. Other authors also reported that lipid digestion products (such as some monoglycerides) at high concentrations $(500 \mu \mathrm{M})$ were cytotoxic to cells (Jia \& Wasan, 2008; Sadhukha, Layek, \& Prabha, 2018).

Permeability studies were carried out with non-digested nanostructures at $25 \mu \mathrm{g} \cdot \mathrm{mL}^{-1}$ of curcumin because results showed that these nanostructures were not cytotoxic for cells at concentrations below 40 $\mu \mathrm{g} \cdot \mathrm{mL}^{-1}$, as previously mentioned. The curcumin $P_{\text {app }}$ values were determined for SLN, NLC and NE after $4 \mathrm{~h}$ incubation, so that they could be compared to other studies. The HPLC chromatograms obtained for each nanostructure for different time of incubation were presented in the Supplementary file (Figs. 1-3). All samples presented different $P_{a p p}$ values $(p<0.05)$ where NLC presented the highest $P_{a p p}$ value $(6.41 \pm$ $\left.2.26 \times 10^{-5} \mathrm{~cm} . \mathrm{s}^{-1}\right)$, followed by SLN $\left(1.96 \pm 0.47 \times 10^{-5} \mathrm{~cm} . \mathrm{s}^{-1}\right)$ and NE $\left(0.195 \pm 0.74 \times 10^{-5} \mathrm{~cm} . \mathrm{s}^{-1}\right)$. The differences between curcumin $P_{a p p}$ values for each nanostructure can be explained by their lipid composition and physical state, since they can influence the curcumin 
permeation route, through free compound diffusion or nanostructures permeation. Neves et al. (2016) reported that NLC showed a higher cellular uptake and permeability than SLN, both with fluorescein isothiocyanate (FITC) incorporated. In order to understand these results, the authors analyzed the transepithelial pathways used by each nanostructure, through the permeability assessment of lucifer yellow and propranolol as the paracellular and transcellular tracers, respectively, when in contact with the nanostructures. They observed that NLC and SLN cross the intestinal barrier predominantly by transcellular route (i.e. transcytosis). However, it was observed that NLC were also able to permeate the intestinal barrier through paracellular transport, once it was observed an increase of the lucifer yellow permeability and a slight decrease of the monolayer resistance in the presence of NLC.

\section{Conclusions}

Results demonstrated that lipid-based nanostructures' physical state and composition influenced curcumin's bioaccessibility, cytotoxicity and intestinal permeability. SLN enhanced particle's stability during in vitro digestion and curcumin intestinal permeability; however, they presented low curcumin's bioaccessibility and stability. On the other hand, NE showed improved curcumin's bioaccessibility and stability, but lower curcumin intestinal permeability and cytotoxic effects after in vitro digestion. NLC showed that the mixture of liquid and solids lipids combine the strengths of NE and SLN. NLC exhibit better particle's stability during in vitro digestion and curcumin intestinal permeability when compared with NE and higher curcumin's bioaccessibility when compared with SLN. Despite MCT oil is considered a GRAS product, MCT oil digestion products presented cytotoxic effects and consequently, digested NLC and NE reduced cell viability. These results showed that it is essential to evaluate GRAS and bio-based ingredients cytotoxicity after in vitro digestion. Therefore, the outcomes of this work have high importance to help on selecting ingredients and design lipid-based nanostructures as enhanced lipophilic compounds vehicles to be applied to food products.

\section{CRediT authorship contribution statement}

Raquel F.S. Gonçalves: Conceptualization, Methodology, Data curation, Writing - original draft. Joana T. Martins: Methodology, Writing - review \& editing. Luís Abrunhosa: Methodology, Writing review \& editing. João Baixinho: Methodology. Ana A. Matias: Supervision. António A. Vicente: Funding acquisition, Supervision, Writing - review \& editing. Ana C. Pinheiro: Conceptualization, Funding acquisition, Supervision, Writing - review \& editing, Validation.

\section{Declaration of Competing Interest}

The authors declare that they have no known competing financial interests or personal relationships that could have appeared to influence the work reported in this paper.

\section{Acknowledgments}

Raquel F. S. Gonçalves acknowledge the Foundation for Science and Technology (FCT) for her fellowship (SFRH/BD/140182/2018). This study was supported by Foundation for Science and Technology (FCT) under the scope of Project PTDC/AGR-TEC/5215/2014, the strategic funding of UIDB/04469/2020 unit and BioTecNorte operation (NORTE01-0145-FEDER-000004) funded by the European Regional Development Fund under the scope of Norte2020 - Programa Operacional Regional do Norte.

Funding from INTERFACE Programme through the Innovation, Technology and Circular Economy Fund (FITEC) and iNova4Health, a program also financially supported by Fundação para a Ciência e
Tecnologia, is also gratefully acknowledged.

\section{Appendix A. Supplementary material}

Supplementary data to this article can be found online at https://doi. org/10.1016/j.foodres.2021.110278.

\section{References}

Aditya, N. P., Macedo, A. S., Doktorovova, S., Souto, E. B., Kim, S., Chang, P. S., \& Ko, S. (2014). Development and evaluation of lipid nanocarriers for quercetin delivery: A comparative study of solid lipid nanoparticles (SLN), nanostructured lipid carriers (NLC), and lipid nanoemulsions (LNE). LWT - Food Science and Technology, 59(1), 115-121. https://doi.org/10.1016/j.lwt.2014.04.058.

Aditya, N. P., Shim, M., Lee, I., Lee, Y., Im, M. H., \& Ko, S. (2013). Curcumin and genistein coloaded nanostructured lipid carriers: In vitro digestion and antiprostate cancer activity. Journal of Agricultural and Food Chemistry, 61(8), 1878-1883. https://doi.org/10.1021/jf305143k.

Bonnaire, L., Sandra, S., Helgason, T., Decker, E. A., Weiss, J., \& McClements, D. J. (2008). Influence of lipid physical state on the in vitro digestibility of emulsified lipids. Journal of Agricultural and Food Chemistry, 56(10), 3791-3797. https://doi. org/10.1021/jf800159e.

Chang, C., Meikle, T. G., Su, Y., Wang, X., Dekiwadia, C., Drummond, C. J., ... Yang, Y. (2019). Encapsulation in egg white protein nanoparticles protects anti-oxidant activity of curcumin. Food Chemistry, 280, 65-72. https://doi.org/10.1016/j. foodchem.2018.11.124.

Chang, Y., \& McClements, D. J. (2016). Influence of emulsifier type on the in vitro digestion of fish oil-in-water emulsions in the presence of an anionic marine polysaccharide (fucoidan): Caseinate, whey protein, lecithin, or Tween 80. Food Hydrocolloids, 61, 92-101. https://doi.org/10.1016/j.foodhyd.2016.04.047.

de Souza, I. D. L., Saez, V., de Campos, V. E. B., \& Mansur, C. R. E. (2019). Size and Vitamin E release of nanostructured lipid carriers with different liquid lipids, surfactants and preparation methods. Macromolecular Symposia, 383(1), 1800011. https://doi.org/10.1002/masy.201800011.

El Kinawy, O. S., Petersen, S., Bergt, K., \& Ulrich, J. (2013). Influence of emulsifiers on the formation and crystallization of solid lipid nanoparticles. Chemical Engineering \& Technology, 36(12), 2174-2178. https://doi.org/10.1002/ceat.201300490.

Faralli, A., Shekarforoush, E., Ajalloueian, F., Mendes, A. C., \& Chronakis, I. S. (2019). In vitro permeability enhancement of curcumin across Caco-2 cells monolayers using electrospun xanthan-chitosan nanofibers. Carbohydrate Polymers, 206, 38-47. https://doi.org/10.1016/j.carbpol.2018.10.073.

Gómez-Estaca, J., Balaguer, M. P., López-Carballo, G., Gavara, R., \& HernándezMuñoz, P. (2017). Improving antioxidant and antimicrobial properties of curcumin by means of encapsulation in gelatin through electrohydrodynamic atomization. Food Hydrocolloids, 70, 313-320. https://doi.org/10.1016/j.foodhyd.2017.04.019.

Helena de Abreu-Martins, H., Artiga-Artigas, M., Hilsdorf Piccoli, R., Martín-Belloso, O., \& Salvia-Trujillo, L. (2020). The lipid type affects the in vitro digestibility and $\beta$-carotene bioaccessibility of liquid or solid lipid nanoparticles. Food Chemistry, 311, Article 126024. https://doi.org/10.1016/j.foodchem.2019.126024.

Himawan, C., Starov, V. M., \& Stapley, A. G. F. (2006). Thermodynamic and kinetic aspects of fat crystallization. Advances in Colloid and Interface Science, 122(1-3), 3-33. https://doi.org/10.1016/j.cis.2006.06.016.

Jia, J. X., \& Wasan, K. M. (2008). Effects of monoglycerides on rhodamine 123 accumulation, estradiol $17 \beta$-D-glucuronide bidirectional transport and MRP2 protein expression within Caco-2 cells. Journal of Pharmacy and Pharmaceutical Sciences, 11(3), 45-62.

Kheradmandnia, S., Vasheghani-farahani, E., Nosrati, M., \& Atyabi, F. (2010). Preparation and characterization of ketoprofen-loaded solid lipid nanoparticles made from beeswax and carnauba wax. Nanomedicine: Nanotechnology, Biology, and Medicine, 6(6), 753-759. https://doi.org/10.1016/j.nano.2010.06.003.

Li, Y., Hu, M., Du, Y., Xiao, H., \& McClements, D. J. (2011). Control of lipase digestibility of emulsified lipids by encapsulation within calcium alginate beads. Food Hydrocolloids, 25(1), 122-130. https://doi.org/10.1016/j.foodhyd.2010.06.003.

Liu, W., Wang, J., McClements, D. J., \& Zou, L. (2018). Encapsulation of $\beta$-caroteneloaded oil droplets in caseinate/alginate microparticles: Enhancement of carotenoid stability and bioaccessibility. Journal of Functional Foods, 40, 527-535. https://doi. org/10.1016/j.jff.2017.11.046.

Ma, P., Zeng, Q., Tai, K., He, X., Yao, Y., Hong, X., \& Yuan, F. (2018). Development of stable curcumin nanoemulsions: Effects of emulsifier type and surfactant-to-oil ratios. Journal of Food Science and Technology, 55(9), 3485-3497. https://doi.org/ 10.1007/s13197-018-3273-0.

McClements, D. J. (2012). Nanoemulsions versus microemulsions: Terminology, differences, and similarities. Soft Matter, 8(6), 1719-1729. https://doi.org/10.1039/ c2sm06903b.

McClements, D. J., \& Xiao, H. (2017). Is nano safe in foods? Establishing the factors impacting the gastrointestinal fate and toxicity of organic and inorganic food-grade nanoparticles. Npj Science of Food, 1(6), 1-13. https://doi.org/10.1038/s41538-0170005-1.

Minekus, M., Alminger, M., Alvito, P., Ballance, S., Bohn, T., Bourlieu, C., ... Brodkorb, A. (2014). A standardised static in vitro digestion method suitable for food-an international consensus. Food and Function, 5(6), 1113-1124. https://doi.org/ 10.1039/c3fo60702j. 
Nayak, P. A., Mills, T., \& Norton, I. (2016). Lipid based nanosystems for curcumin: Past, present and future. Current Pharmaceutical Design, 22(27), 4247-4256. https://doi. org/10.2174/1381612822666160614083412.

Neves, A. R., Queiroz, J. F., Costa Lima, S. A., Figueiredo, F., Fernandes, R., \& Reis, S. (2016). Cellular uptake and transcytosis of lipid-based nanoparticles across the intestinal barrier: Relevance for oral drug delivery. Journal of Colloid and Interface Science, 463, 258-265. https://doi.org/10.1016/j.jcis.2015.10.057.

Ozturk, B., Argin, S., Ozilgen, M., \& McClements, D. J. (2014). Formation and stabilization of nanoemulsion-based vitamin e delivery systems using natural surfactants: Quillaja saponin and lecithin. Journal of Food Engineering, 142, 57-63. https://doi.org/10.1016/j.jfoodeng.2014.06.015.

Park, S. J., Garcia, C. V., Shin, G. H., \& Kim, J. T. (2017). Development of nanostructured lipid carriers for the encapsulation and controlled release of vitamin D3. Food Chemistry, 225, 213-219. https://doi.org/10.1016/j.foodchem.2017.01.015.

Perrone, D., Ardito, F., Giannatempo, G., Dioguardi, M., Troiano, G., Lo Russo, L., ... Lo Muzio, L. (2015). Biological and therapeutic activities, and anticancer properties of curcumin. Experimental and Therapeutic Medicine, 10(5), 1615-1623. https://doi.org/ 10.3892/etm.2015.2749.

Pimentel-Moral, S., Teixeira, M. C., Fernandes, A. R., Arráez-Román, D., MartínezFérez, A., Segura-Carretero, A., \& Souto, E. B. (2018). Lipid nanocarriers for the loading of polyphenols - A comprehensive review. Advances in Colloid and Interface Science, 260, 85-94. https://doi.org/10.1016/j.cis.2018.08.007.

Pinheiro, A. C., Coimbra, M. A., \& Vicente, A. A. (2016). In vitro behaviour of curcumin nanoemulsions stabilized by biopolymer emulsifiers - Effect of interfacial composition. Food Hydrocolloids, 52, 460-467. https://doi.org/10.1016/j. foodhyd.2015.07.025.

Qian, C., Decker, E. A., Xiao, H., \& McClements, D. J. (2013). Impact of lipid nanoparticle physical state on particle aggregation and $\beta$-carotene degradation: Potential limitations of solid lipid nanoparticles. Food Research International, 52(1), 342-349. https://doi.org/10.1016/j.foodres.2013.03.035.

Sadhukha, T., Layek, B., \& Prabha, S. (2018). Incorporation of lipolysis in monolayer permeability studies of lipid-based oral drug delivery systems. Drug Delivery and Translational Research, 8(2), 375-386. https://doi.org/10.1007/s13346-017-0383-6.

Sarkar, A., Goh, K. K. T., \& Singh, H. (2009). Colloidal stability and interactions of milkprotein-stabilized emulsions in an artificial saliva. Food Hydrocolloids, 23(5), 1270-1278. https://doi.org/10.1016/j.foodhyd.2008.09.008.

Serra, A. T., Matias, A. A., Almeida, A. P. C., Bronze, M. R., Alves, P. M., de Sousa, H. C., \& Duarte, C. M. M. (2011). Processing cherries (Prunus avium) using supercritical fluid technology. Part 2. Evaluation of SCF extracts as promising natural chemotherapeutical agents. The Journal of Supercritical Fluids, 55(3), 1007-1013. https://doi.org/10.1016/j.supflu.2010.06.006.
Shu, G., Khalid, N., Tan, T. B., Zhao, Y., Neves, M. A., Kobayashi, I., \& Nakajima, M. (2018). In vitro bioaccessibility of ergocalciferol in nanoemulsion-based delivery system: The influence of food-grade emulsifiers with different stabilising mechanisms. International Journal of Food Science \& Technology, 53(2), 430-440. https://doi.org/10.1111/ijfs.13601.

Silva, D. S., Almeida, A., Prezotti, F. G., Facchinatto, W. M., Colnago, L. A., CampanaFilho, S. P., \& Sarmento, B. (2017). Self-aggregates of 3,6-O, O'-dimyristoylchitosan derivative are effective in enhancing the solubility and intestinal permeability of camptothecin. Carbohydrate Polymers, 177, 178-186. https://doi.org/10.1016/j. carbpol.2017.08.114.

Silva, H. D., Beldíková, E., Poejo, J., Abrunhosa, L., Serra, A. T., Duarte, C. M. M., ... Vicente, A. A. (2019). Evaluating the effect of chitosan layer on bioaccessibility and cellular uptake of curcumin nanoemulsions. Journal of Food Engineering, 243, 89-100. https://doi.org/10.1016/j.jfoodeng.2018.09.007.

Soleimanian, Y., Goli, S. A. H., Varshosaz, J., \& Sahafi, S. M. (2018). Formulation and characterization of novel nanostructured lipid carriers made from beeswax, propolis wax and pomegranate seed oil. Food Chemistry, 244, 83-92. https://doi.org/ 10.1016/j.foodchem.2017.10.010.

Souto, E. B., \& Doktorovová, S. (2009). Solid lipid nanoparticle formulations: Pharmacokinetic and biopharmaceutical aspects in drug delivery. Methods in Enzymology, 464, 105-129. https://doi.org/10.1016/S0076-6879(09)64006-4.

Swarnakar, N. K., Venkatesan, N., \& Betageri, G. (2019). Critical in vitro characterization methods of lipid-based formulations for oral delivery: A comprehensive review. AAPS PharmSciTech, 20(1), 16. https://doi.org/10.1208/s12249-018-1239-1.

Tamjidi, F., Shahedi, M., Varshosaz, J., \& Nasirpour, A. (2014). Design and characterization of astaxanthin-loaded nanostructured lipid carriers. Innovative Food Science \& Emerging Technologies, 26, 366-374. https://doi.org/10.1016/j. ifset.2014.06.012.

Tang, C.-H. (2020). Nanocomplexation of proteins with curcumin: From interaction to nanoencapsulation (A review). Food Hydrocolloids, 109, Article 106106. https://doi. org/10.1016/j.foodhyd.2020.106106.

Zimmermann, E., \& Müller, R. H. (2001). Electrolyte- and pH-stabilities of aqueous solid lipid nanoparticle $\left(\mathrm{SLN}^{\mathrm{TM}}\right)$ dispersions in artificial gastrointestinal media. European Journal of Pharmaceutics and Biopharmaceutics, 52(2), 203-210. https://doi.org/ 10.1016/S0939-6411(01)00167-9.

Zou, L., Zheng, B., Zhang, R., Zhang, Z., Liu, W., Liu, C., ... McClements, D. J. (2016). Influence of lipid phase composition of excipient emulsions on curcumin solubility, stability, and bioaccessibility. Food Biophysics, 11(3), 213-225. https://doi.org/ 10.1007/s11483-016-9432-9. 